\title{
artigo
}

Oliveira, T.S.; Duamarde, L.T.L.; Coura, E.A.; Faria, G.P.G.; Unsonst Filho, J.; Antunes, L.S.;

SORORIDADE NA ENFERMAGEM: dando voz às mulheres negras vitimas de violência

\section{SORORIDADE NA ENFERMAGEM: dando voz às mulheres negras vítimas de violência}

\author{
SORORITY IN NURSING: giving voice to black women victims of violence \\ SORORIDAD EN ENFERMERÍA: dar voz a las mujeres negras víctimas de violencia
}

\begin{abstract}
RESUMO
Como objetivo desta pesquisa estabeleceu-se descrever o impacto da violência doméstica sofrida nas mulheres negras, no município de Cabo Frio e elaborar uma palestra informativa sobre a violência doméstica e suas consequências para a mulher negra e sua família. Tratou-se de uma pesquisa descritivo-exploratória com abordagem qualitativa. Foram entrevistadas 03 mulheres, participantes da Rede das Pretas. Todas as entrevistadas sofreram a violência psicológica, por ser uma violência de difícil identificação nenhum dos agressores foi denunciado. No entanto, essas vítimas conseguiram romper o ciclo da violência e viver longe de seus agressores. Foi visto que alguns dados divergiram da literatura em relação ao perfil do agressor e nível de escolaridade das mulheres. Conclui-se que os objetivos foram alcançados, visto que foi possivel descrever o impacto da violência doméstica sofrida nas mulheres negras, no município de Cabo Frio. Esta pesquisa tem ampla importância à sociedade, pois corrobora para admissão de melhores condutas no acolhimento às mulheres vítimas de violência doméstica. Na enfermagem, ela mostra-se relevante para um aperfeiçoamento profissional, adoção de uma assistência humanizada, estabelecida na sororidade e empatia.
\end{abstract}

DESCRITORES: Violência Contra à Mulher; Violência Doméstica; Violência de Gênero; Enfermagem; Grupo com Ancestrais do Continente Africano.

\section{ABSTRACT}

The objective of this research was to describe the impact of domestic violence suffered on black women in the municipality of Cabo Frio and to prepare an informative lecture on domestic violence and its consequences for black women and their families. It was a descriptive-exploratory research with a qualitative approach. Three women were interviewed, participating in Rede das Pretas. All the interviewees suffered psychological violence, as it is difficult to identify violence, none of the aggressors was reported. However, these victims managed to break the cycle of violence and live far from their aggressors. It was seen that some data diverged from the literature in relation to the profile of the aggressor and the level of education of women. It is concluded that the objectives were achieved, since it was possible to describe the impact of domestic violence suffered on black women, in the municipality of Cabo Frio. This research is of great importance to society, as it supports the admission of better conduct in welcoming women victims of domestic violence. In nursing, it is relevant for professional improvement, the adoption of humanized assistance, established in sorority and empathy.

DESCRIPTORS: Violence Against Women; Domestic Violence; Gender-Based Violence; Nursing; African Continental Ancestry Group.

\section{RESUMEN}

El objetivo de esta investigación fue describir el impacto de la violencia doméstica sufrida en las mujeres negras en el municipio de Cabo Frio y preparar una conferencia informativa sobre la violencia doméstica y sus consecuencias para las mujeres negras y sus familias. Fue una investigación descriptiva-exploratoria con un enfoque cualitativo. Tres mujeres fueron entrevistadas, participando en Rede das Pretas. Todos los entrevistados sufrieron violencia psicológica, ya que es difícil identificar la violencia, no se informó de ninguno de los agresores. Sin embargo, estas víctimas lograron romper el ciclo de violencia y vivir lejos de sus agresores. Se vio que algunos datos divergían de la literatura en relación con el perfil del agresor y el nivel de educación de las mujeres. Se concluye que se alcanzaron los objetivos, ya que fue posible describir el impacto de la violencia doméstica sufrida en las mujeres negras, en el municipio de Cabo Frio. Esta investigación es de gran importancia para la sociedad, ya que apoya la admisión de una mejor conducta en la acogida de mujeres víctimas de violencia doméstica. En enfermería, es relevante para la mejora profesional, la adopción de asistencia humanizada, establecida en hermandad y empatía.

DESCRIPTORES: Violencia Contra la Mujer; Violencia Doméstica; Violencia de Gènero; Enfermería; Grupo de Acendencia Continental Africana.

RECEBIDO EM: 06/12/2019 APROVADO EM: 09/12/2019 


\section{Patrícia da Costa Teixeira}

Mestre em Enfermagem pela Universidade do Estado do Rio de Janeiro. Professora da Universidade Veiga de Almeida - Campus Cabo Frio - RJ. ORCID: 0000-0002-1338-6091

\section{Thaís da Silva Oliveira}

Acadêmica de Enfermagem da Universidade Veiga Almeida - Campus Cabo Frio. ORCID: https://orcid.org/0000-0002-6461-201X

\section{Leila Tomazinho de Lacerda Duamarde}

Mestre em saúde, sociedade e psicanálise; Doutoranda em educação e saúde; Professora da Universidade Veiga de Almeida Cabo Frio, RJ. ORCID: 0000-0002-3344-5298

\section{Evelyn Alves Coura}

Acadêmica de Enfermagem da Universidade Veiga de Almeida - Campus Cabo Frio. https://orcid.org/0000-0002-9050-3618

Gabriela Priscila Goveia Faria

Acadêmica de Enfermagem da Universidade Veiga de Almeida - Campus Cabo Frio. ORCID: 0000-0002-7652-0796

\section{Jorge Unsonst Filho}

Acadêmico de Enfermagem da Universidade Veiga de Almeida - Campus Cabo Frio. https://orcid.org/0000-0002-2918-1525

\section{Ludmila Santos Antunes}

Acadêmica de Enfermagem da Universidade Veiga de Almeida - Campus Cabo Frio. ORCID: 0000-0002-9865-3282

\section{INTRODUÇÃO}

A violência de gênero é existente em todo o mundo, segundo a Organização Mundial da Saúde (OMS), cerca de uma em cada três mulheres (35\%) no mundo inteiro foi vítima de violência física e/ou sexual por parte do cônjuge ou de terceiros durante a vida ${ }^{(1)}$.

O Mapa da Violência 2015, realizado pela Faculdade Latino-Americana de Ciências Sociais (Flacso), indica um crescimento de $54 \%$ em dez anos no número de feminicídio contra mulheres negras, excedendo de 1.864, em 2003, para 2.875, em 2013. Com o percentual de 4,8 assassinatos para $100 \mathrm{mil}$ mulheres, o Brasil está entre os países com maior taxa de femínicidio: esta na quinta colocação em um ranking de 83 nações. Pesquisas apresentaram que entre os anos de 2005 e 2015, a mortalidade das mulheres negras cresceu $22 \%$, apontando uma taxa acima da média nacional. Com o índice de 5,2 assassinatos para 100 mil mulheres, as mulheres negras são $65,3 \%$ das vítimas de violência seguida de morte ${ }^{(2)}$.

Recentemente, o Atlas da Violência 2019 apresentou dados que indicam o índice de homicídios de mulheres não negras teve um aumento de 4,5\% entre 2007 e 2017, enquanto a taxa de homicídios de mulheres negras cresceu 29,9\%. Em números totais, a diferença é ainda mais cruel, já que entre não negras o aumento é de $1,7 \%$ e entre mulheres negras de $60,5 \%$. Tendo em vista o último ano disponível, o índice de homicídios de mulheres não negras foi de $3,2 \%$ a cada 100 mil mulheres não negras, à medida que entre as mulheres negras a taxa foi de 5,6\% para cada 100 mil mulheres. As mulheres negras permanecem sendo as que mais morrem no país, certificamos esses dados quando observamos a proporção de mulheres negras entre as vítimas de violência fatal: $66 \%$ de todas as mulheres mortas no país em $2017^{(3,4)}$.

Segundo o Instituto Brasileiro de Geografia e Estatística (IBGE), no ano de 2010, a população negra feminina, no Estado do Rio de Janeiro, era de 354.880 , entre a faixa etária de 19 a 50 anos $^{(5)}$.

No Estado do Rio de Janeiro, no primeiro semestre de 2018, a Central Telefônica de Atendimento à Mulher (Ligue 180) registrou: 14 feminicídios, 17 homicídios, 3.018 tentativas de feminicídio e 43 tentativas de homicí- dios. No mesmo período, os relatos de violência chegaram a 38.681, sendo os maiores números referentes à violência física (16.615) e violência psicológica (12.745). Os agressores são, na sua maioria, os próprios companheiros ${ }^{(6)}$.

$\mathrm{O}$ conceito de violência contra mulher na Lei Maria da Penha n. ${ }^{\circ}$ 11.340/2006 tem como definição de violência domiciliar e familiar: "Configura violência doméstica e familiar contra a mulher qualquer ato ou conduta baseada no gênero que cause morte, dano ou sofrimento físico, sexual, psicológico e dano moral ou patrimonial". A agressão pode manifestar-se de diversas formas: física, psicológica, sexual, patrimonial e moral ${ }^{(7)}$.

A violência de gênero tornou-se uma questão social somente em meados da década de 70. Com base em situações que cônjuges e ex cônjuges eram permitidos assassinar e agredir em defesa da dignidade e honradez. Porém, no início, o Estado não assumiu a responsabilidade do enfrentamento contra a violência doméstica, fazendo com que o movimento feminista passasse a viabilizar ações diretas para combater essa crueldade ${ }^{(8)}$.

Em decorrência dos elevados homicídios femininos, o feminicídio "é 
definido como homicídio de mulheres motivado pela violência doméstica, familiar ou por discriminação pela condição de mulher" ${ }^{\prime 9}$.

Sancionada no dia 9 de março de 2015 pela presidenta Dilma Rousseff, a Lei do Feminicídio, altera o Art. 121 do Decreto - Lei $n .^{\circ} 2.848$, de 7 de dezembro de 1940 - Código Penal, para prever o feminicídio como circunstância qualificadora do crime de homicidio, e o Art. $1^{\circ}$ da Lei.$^{\circ} 8.072$, de 25 de julbo de 1990, para incluir o feminicídio no rol dos crimes hediondos $^{(10)}$.

A publicação dessa Lei é o resultado de uma sequência de documentos internacionais planejados pela Organização Nações Unidas (ONU) com a finalidade de cessar as agressões sofridas por mulheres em situação de violência doméstica ${ }^{(11)}$.

Com base na procura por redes de apoio, foram identificados os órgãos e serviços que atuam no amparo às mulheres e suas famílias, apresentadas a seguir: Central de Atendimento 180, Delegacias Especiais de Atendimento à Mulher (DEAM), Conselho Estadual dos Direitos da Mulher (CEDIM), Núcleo Especializado no Atendimento à Mulher Vítima de Violência (NUDEM), Central Judiciária de Abrigamento Provisório da Mulher Vítima de Violência - CEJUVIDA ${ }^{(12)}$.

Em consequência do alto índice de violência de gênero e feminicídio, alguns questionamentos emergiram, tais como: Qual o impacto da violência nas mulheres negras? Quais os tipos de violência vivenciados por estas mulheres? Elas dispuseram de alguma rede de apoio para o enfrentamento desta situação?

Desta forma, definiu-se como objeto de estudo as mulheres negras vítimas de violência doméstica. E como objetivo desta pesquisa, estabeleceu-se descrever o impacto da violência doméstica sofrida nas mulheres negras, no município de Cabo Frio e elaborar uma palestra informativa sobre a violência doméstica e suas consequências para a mulher negra e sua família.

Consequentemente, este estudo justifica-se por sua grande relevância à sociedade, já que contribui para a adoção de melhores práticas no acolhimento a mulheres vítimas de violência doméstica. Já na enfermagem, mostra-se importante para uma melhoria profissional, adoção de uma assistência humanizada, constituída na sororidade e empatia. $\mathrm{Na}$ esfera acadêmica, este estudo se apresenta importante, visto que, devido ao alto índice de feminicídio em consequência da violência de gênero, é essencial ao estudo através de referências atuais. Auxilia também como guia e referência para outros trabalhos posteriores, sendo capaz de colaborar como meio de educação continuada e na própria formação acadêmica.

\section{METODOLOGIA}

Esta pesquisa se deu através de um estudo do tipo descritivo-exploratório com abordagem qualitativa. $\mathrm{O}$ tipo de pesquisa descritiva objetiva, primordialmente, à descrição das peculiaridades de determinada população ou fenômeno; enquanto a exploratória tem como meta familiarizar o pesquisador com o problema, com o intuito de torná-lo mais explícito ou construir hipóteses. Os dados qualitativos consistem em descrições detalhadas de situações com o objetivo de compreender os indivíduos em seus próprios termos ${ }^{(13,14)}$.

O estudo teve como cenário de pesquisa um núcleo de assistência à mulher negra vítima de violência doméstica, referência no atendimento à mulher negra, e foi iniciado após a aprovação do projeto de Monografia I e pelo Comitê de Ética em Pesquisa da Universidade Veiga de Almeida através do parecer n. ${ }^{\circ}$ 3.697.135. Os sujeitos foram (03) mulheres. O método de coleta de dados se deu realizado mediante os gravadores de voz e caracterização dos sujeitos e roteiro semiestruturado e checklist, sendo considerado o melhor método para descrição fidedigna das narrativas relatadas pelas entrevistadas. Critérios de inclusão: mulheres negras maiores de 18 anos que vivenciaram a violência doméstica. E como critério de exclusão, mulheres que não vivenciaram a violência doméstica.

O estudo utilizou o Termo de Consentimento Livre e Esclarecido (TCLE) para uso das respostas frente à entrevista, foram respeitados os preceitos éticos da legalidade da Resolução n. ${ }^{\circ} 466$, do Conselho Nacional da Saúde, de 12 de dezembro de 2012, que legaliza o estudo de seres humanos em território brasileiro. O presente estudo não previu nenhum custo para a instituição onde foi executado e nem tampouco, a qualquer um dos participantes. Foi realizado utilizando apenas nomes fictícios dos sujeitos, respeitando o sigilo.

A análise de dados do projeto foi baseada na análise temática de Bardin, uma proposta qualitativa de avaliação do conteúdo para as discussões dos resultados futuros ${ }^{(15,16)}$.

As autoras Marconi e Lakatos ${ }^{(17)}$ definem "a análise do conteúdo tem por característica a formulação de categorias para a análise, que tanto podem ser inspiradas na literatura como método Bardin”, e essa metodologia de análise foi utilizada nesse estudo.

\section{RESULTADOS E DISCUSSÃO}

Com relação à contrução desta pesquisa, foi essencial altear o perfil sociodemográfico das mulheres, as redes de proteção e apoio e os tipos de violência vivenciada, tais dados estão representados na caracterização dos sujeitos. Em seguida, as falas foram interpretadas e agrupadas por semelhança. Com isso, a análise e discussão dos dados seguiu a seguinte sequência: Caracterização dos sujeitos; Agressão e os impactos que sobrepassam aos danos psicológicos; Perfil do agressor; e Rompendo com o ciclo da violência doméstica. 


\section{Caracterização dos sujeitos}

Para elaboração do presente trabalho, foram efetuadas entrevistas gravadas com vítimas de violência doméstica integrantes da Rede das Pretas, entre os meses de setembro e outubro de 2019. Também foi realizada uma pesquisa empírica que buscou delinear o perfil sociodemográfico de mulheres que ali buscaram apoio e força. Destaca-se que as observações ora expostas referem-se à violência psicológica às mulheres por seus ex-companheiros. $\mathrm{Na}$ Tabela 1, pode-se observar os principais dados socioeconômicos das mulheres entrevistadas.

Como se pode ver acima, no quesito religião, houve uma semelhança nas respostas, sendo $33,3 \%$ o número de mulheres que são evangélicas, candomblecistas e espiritualistas. Pesquisas recentes mostram que há um indicativo crescente de mulheres autodeclaradas evangélicas que procuram os setores de atendimento expondo os mais diversos tipos de violência praticada por seus parceiros ${ }^{(18)}$. Todas as integrantes desta pesquisa em determinados momentos recorreram à igreja cristã em busca de auxilio e amparo para o enfrentamento dessas violências.

Todas as mulheres que participaram

Tabela 1. Perfil sociodemográfico das mulheres. Cabo Frio, Rio de Janeiro, Brasil, 2019.

\section{Variáveis}

Cor - Negra

Ensino Superior

Profissão

Advogada

Enfermeira

Analista de Cont. De Qualidade

Religião

Candomblecista

Espiritualista

Evángelica

Estado Civil

Casada

Divorciada

Separada de corpo

Filhos

Sim

02 66,6

Não

01

\section{Tabela 2. Redes de proteção e apoio. Cabo Frio, RJ, Brasil 2019.}

Variáveis

$\mathrm{N}^{\circ}$

$\%$

\section{Suporte Familiar}

Sim

03

100

Não

Medidas Protetivas

Sim

Não

03 deste estudo se autodeclararam de cor negra. Recentemente, o Atlas da Violência 2019 exibiu dados que apontam que o índice de homicídios de mulheres negras cresceu 29,9\% entre 2007 e 2017. Em referências absolutas, o crescimento é $60,5 \%$. Considerando-se o último ano disponível, a taxa de homicídio para mulheres negras foi de 5,6\% para cada 100 mil mulheres neste grupo. Os registros são alarmantes quando observamos a proporção de mulheres negras vitimas de violência letal, $66 \%$ de todas as mulheres mortas no país em $2017^{(4)}$.

Em totalidade $100 \%$ das entrevistadas possuem o ensino superior completo: $33,33 \%$ são advogadas, 33,33\% são enfermeiras e $33,33 \%$ são analistas de controle de qualidade. A média de idade dessas mulheres é de 41 anos e 3 meses.

Apenas 1,3\% dessas mulheres têm filhos. $66,66 \%$ são divorciadas e $33,33 \%$ relatou que é separada de corpo. Segundo o Código de Processo Civil "A separação de corpos é uma medida judicial que tem por escopo a saída ou a retirada de um dos cônjuges do lar conjugal, por autorização judicial, espontânea ou compulsoriamente"(19).

Dentre as entrevistadas, $100 \%$ garantiram que tiveram suporte familiar quando esclareceram para a família sobre a violência sofrida. É importante introduzir uma estratégia de apoio e base social para que seja apto construir um método de cuidado disposto a viabilizar a saúde mental dos envolvidas e, especificamente, para que a vivência de violência vivida pelas mulheres não consista, no futuro, um padrão de identificação para os filhos ${ }^{(20)}$.

Em relação às medidas protetivas, $100 \%$ afirmaram não terem possuído medidas protetivas. Destaca-se que, em maio de 2019, o Presidente da República sancionou a Lei n. ${ }^{\circ} 13.827$, de 13 de maio de 2019 que:

Altera a Lei.$^{\circ} 11.340$, de 7 de agosto de 2006 (Lei Maria da Penha), para autorizar, nas hipóteses que especifica, a aplicação de medida protetiva de urgência, pela autori- 
dade judicial ou policial, à mulher em situação de violência doméstica e familiar, ou a seus dependentes, $e$ para determinar o registro da medida protetiva de urgência em banco de dados mantido pelo Conselho Nacional de Justiça ${ }^{(21)}$.

De acordo com os dados apresentados, das 03 mulheres que foram auxiliadas pela Rede das Pretas, as 03 foram vítimas de violência doméstica: física, psicológica e moral; psicológica e sexual; psicológica e patrimonial, respectivamente.

A rede de enfrentamento à violência contra as mulheres refere-se à ação planejada entre as entidades governamentais, não-governamentais e a sociedade, objetivando o progresso de estratégias efetivas de prevenção e de políticas que assegurem a edificação da independência das mulheres, os seus direitos humanos e a assistência qualificada às mulheres vítimas de violência doméstica ${ }^{(22)}$.

A violência está relacionada à posição desigual das mulheres nas relações e ao "poder" masculino ao domínio sobre bens, condutas e atitudes femininas, de modo que, quando a mulher desfaz essa autoridade ou o homem não pode mantê-lo, se designa a violência ${ }^{(23)}$.

Os tipos mais comuns de violência são: a violência física que é prática violenta, na qual se fez uso da força física de forma proposital com a finalidade de lesionar, causar dor e sofrimento ou provocar ferimentos no seu corpo; a psicológica, que é qualquer conduta que tenha o objetivo de danificar ou reprimir as ações e comportamentos; a sexual é a obrigatoriedade sobre a vítima a assistir, manter ou participar de relação sexual não pretendida; a patrimonial que se caracteriza como qualquer conduta que configure retenção, destruição parcial ou total de seus objetos, documentos pessoais, valores e direitos ou recursos econômicos; e a moral, que é ação destinada a detrair, infamar, desonrar ou injuriar o nome e a imagem da mulher ${ }^{(7,24)}$.

\section{Agressões e os impactos que sobrepas- sam aos danos psicológicos da Mulher}

A violência contra a mulher possui uma ampla abrangência, onde é possível constatar no Art. $7^{\circ}$ Inciso II a violência psicológica. De acordo com pesquisas recentes, a violência psicológica é a segunda maior agressão sofrida por mulheres em situação de violência doméstica. Embora haja a Lei n. ${ }^{\circ} 11.340 / 2006$, popularmente conhecida como Lei Maria da Penha, ainda há dificuldade em identificar esse tipo de violência por ser realizada silenciosamente e sem deixar sinais perceptíveis. Nesse estudo foi possivel indentificar que a maior agressão sofrida pelas mulheres foi a psicologica, que diverge com as literaturais atuais ${ }^{(5,25)}$.

Em relação à primeira categoria temática, foi possível compreender a vulnerabilidade dessas mulheres diante do cenário de violência vivida, identificadas nas falas a seguir:

"A primeira agressão foi à psicológica. Ele abaixava a minha autoestima o tempo todo. Falava que eu era feia, gorda, metida a inteligente porque eu queria saber tudo. 2uando eu me maquiava, eu era igual um perro. Um tempo depois, deu inicio as agressões físicas. Foram 11 anos vivendo esse relacionamento" (Pinheiro).

"Eu fui vitima da agressão psicológica, na verdade eu não queria ver, sabe?! Logo no começo já mostrava ser assim, mas ele dizia que ia mudar. E com isso nós ficamos 04 anos casados" (Cacto).

"Eu sofri a violência psicológica, ele colocou muito a minha vida em risco, em conversas normais com toda a calma do mundo, se ele discordasse de alguma coisa que eu falasse coisas simples, básicas do dia - a dia. Nesses dois anos e oito meses de casamento, ele socava a sanduicheira, socou a porta da casa, já socou a pilastra da parede e várias e várias coisas" (Acácia).

A violência praticada pelo parceiro íntimo tem um impacto significativo nos indivíduos, nas famílias, comunidade e na sociedade. Os epísodios constantes de violência tornam-se um conjunto de danos físicos e psicológicos para a mulher que sofre agressão do companheiro maltratante. As consequências mais comuns são lesões físicas e cerebrais, por vezes irreversíveis (e.g., perda de dentes, fraturas de costelas, lesões abdominais). Nesta presente pesquisa, não foram identificados danos cerebrais, entretanto, houve uma unanimidade em relação à alteração do padrão de sono e perturbações alimentares; sentimentos de medo, vergonha e culpa ${ }^{(26,27)}$.

Quando se analisa a dimensão psíquica da violência psicológica, percebe-se que os resultados da violência contra a mulher, independente da sua forma de manifestação, estão relacionados a uma multiplicidade de causas psicossociais e psicológicas. Problemas de saúde mentais e físicos, contendo: dores musculares, isolamento, angústia, aflição, inquietação e depressão ${ }^{(28)}$.

Estes sintomas considerados psíquicos podem ser analisados nas falas a seguir:

"Ta fazendo um ano e desde então eu nunca mais me recuperei fisicamente, eu não sou a mesma fisicamente, porque a dor, a emoção foi se transformando nessa doença física que tem um fundo emocional. Eu fui ao reumatologista e ele tinha me liberado do tratamento da Chikungunya, voltei pra falar que já tava um ano sem tratamento, mas eu continuava sentindo dor. Foi quando ele falou que não era mais da Chikungunya, fiz os exames $e$ tal, mas provavelmente é Fribromialgia. Hoje faço uso de um medicamento que trata a depressão $e$ a dor. Ah, a ansiedade também. $A$ ansiedade se tornou uma coisa comum, assim. Já melhorou, tem hora que piora, tem hora que melhora, mas é ansiedade, preocupação com as coisas de casa" (Cacto). 
"[...] veio à depressão e aí eu comecei a ter que fazer tratamentos com psicólogo e psiquiatra, tendo que tomar medicamentos, porque só a terapia não ajudava naquele momento. Eu acabei tendo uma depressão pós-aborto, porque eu sofri um aborto espontâneo" (Acácia).

"Mas eu penso que eu só queria ser apaixonada por alguém que fosse apaixonado por mim, na verdade, essa lacuna nunca foi preenchida, porque eu não consigo ter relacionamentos legais depois disso, eu não confio em ninguém. Eu trato todo mundo mal, quem fica comigo, fica porque quer, eu acho que sou meio agressiva" (Pinheiro).

É possível observar as semelhanças nas argumentações das entrevistadas quando manifestam os acontecimentos vividos com seus ex-companheiros. Com isso, podemos identificar sintomas psíquicos, como: ansiedade, depressão e o receio em se relacionar novamente, recorrente aos episódios de violência.

O ex Secretário Geral da Organização das Nações Unidas (ONU), Kofi Annan, declarou que "a violência contra as mulheres causa enorme sofrimento. Impedindo que as mulheres realizem as suas potencialidades, limita o crescimento econômico e compromete o desenvolvimento" ${ }^{(29)}$.

"Ninguém sai ilesa de tanta violência, eu não gosto de atender violência doméstica no escritório. Eu não gosto de atender vitima, não trabalho bem com esse público. Porque eu acho que todo mundo tem que reagir igual eu reagi. E não é assim, as pessoas têm medo, mas eu não tive medo. Eu não tive medo! Eu poderia ter morrido e eu falava pra ele que não ia virar estatística, que não ia morrer. 2uando tive outros relacionamentos, fiquei neurótica, gritava um pouquinho e eu pensava que era violência e falava que não gostava que falasse naquele tom comigo" (Pinheiro).

À vista disso, nota-se que no presente estudo há uma entrevistada que não consegue realizar seu trabalho de uma forma plena, pois revive todos os episódios de violência psicológica que sofreu enquanto era casada com o agressor, dificultando a execução de seu ofício.

Agressão e os impactos que sobrepassam aos danos psicológicos atingindo os filhos

É possível notar as perspectivas das integrantes da pesquisa sobre as consequências formadas em seus filhos em função das violências que sofreram. No começo, essas crianças foram expostas de forma indireta em uma relação matrimonial em que ocorria desrespeito, agressividade e insulto, conforme ficou identificado nos depoimentos a seguir:

"[...] Meu filho via, minha filha via. Mas minha filha não deve lembrar porque era pequenininha, mas meu filho via. [...] eu sei que meu filho é um cara problemático, mas eu o criei pra ser um cara bacana, pra respeitar as mulheres" (Pinheiro).

"Minha filha caçula de doze anos é muito antenada falou para mim que nunca vai ter um homem igual ao pai. Então ela tem noção do que o pai fazia não era legal. Tem o avô, que tem o mesmo perfil, o pai do pai. Ela foi passar o dia dos pais com o pai e com o avô e quando ela chegou me disse que não quer mais estar com eles, pois é uma família tóxica. Eu não quero obrigar, mas a gente ainda tem que vivenciar isso. [...] depois que ele foi embora, a gente conseguiu se abrir e falar mais da realidade do homem. A minha filha mais velha namora uma menina já tem 01 ano e pouco, tá bem. Ela é bissexual, já namorou, não namorou fixo como ela namora essa menina, mas ela já teve flertes com meninos, mas hoje ela namora essa menina que é minha nora" (Cacto).

As crianças expostas ao comportamento abusivo do agressor estão sujeitas a desencadear a violência como modo de viver e problemas sociais, emocionais e psicológicos, como: ansiedade, depressão, baixo rendimento escolar e desobediência ${ }^{(30)}$.

Desta forma, identifica-se que crianças que assistem episódios constantes de violência doméstica têm a possibilidade de se tornarem adultos maltratantes ou adultos que não toleram vivenciar nenhum tipo de violência. Não foi possível identificar em outros estudos que a bissexualidade ocorra por conta do trauma da violência doméstica.

\section{Perfil do agressor}

$\mathrm{O}$ agressor, normalmente, segue um padrão de comportamento muito específico, regido por ações comuns em todos os episódios de violência, conhecido como ciclo da violência doméstica. Ao serem questionadas a respeito do perfil de seus ex-parceiros, a manipulação e ameaças são citadas constantemente, como se pode observar nas falas abaixo:

"Existia uma manipulação para me dominar, para eu ficar no julgo dele. [...] Desde que eu não quisesse fazer nada sozinha, quisesse minha liberdade, minha individualidade. [...] Houve muitas ameaças de morte, porque ele achava que eu o traia. Ai começou a me ameaçar. [...] ele foi ficando paranóico" (Pinheiro).

"Ele era um homem muito possessivo, ciumento, mau caráter. Era um dominio! No meu celular, nas minhas redes sociais, nas pessoas que eu convivia, aonde eu ia. [...] Ele era muito manipulador" (Cacto).

A violência praticada pelo parceiro íntimo envolve diversas agressões que, na sua maioria, são atos que ocorrem de formas freqüentes que vão se intensificando com o passar dos anos, como: censura, difamação, intimidação, ameaças e agressão psíquica $^{(31)}$. 


\section{artigo}

Embora existam estudos delineando as características e os motivos que influenciam o homem a se tornar um agressor, não é possível determinar um perfil específico de um companheiro maltratante. No entanto, apesar de ser difícil definir as causas que são capazes de estimar este tipo de agressão, expõe-se que: há uma quantidade significativa de homens que possuem a necessidade de autoridade e manipulação sobre a mulher; tem receio da autonomia, liberdade e confiança de sua parceira; dessa forma, esses homens manifestam a raiva quando percebem que estariam perdendo o domínio, a influência e a autoridade frente à mulher e seu relacionamento ${ }^{(32)}$.

"Eu aparecer mais que ele era algo que irritava então ele sempre queria me podar. Ele é um cara que te digo, eu acho que ele tem problemas psiquiátricos. Além do mau caratismo, ele se deu conta de que a manipulação, a mentira trabalha o ego dele e ele faz isso sempre pra se sentir bem e importante. Ele tem desequilíbrio, ele tem um desequilíbrio muito grande" (Cacto).

Mulheres em situação de violência acreditam que têm responsabilidade sobre o comportamento agressivo do seu parceiro. Em alguns casos, o agressor usa a força física para amedrontar e aprisionar a companheira nessa relação violenta. $\mathrm{O}$ medo vivenciado diariamente por essas mulheres e a apreensão por não saberem a causa de provocar novos episódios de raiva dos agressores é um fator relevante para se tornarem permissivas em relação à agressão sofrida ${ }^{(24,29)}$.

"[...] ele pegou e deu um soco na pilastra que o sangue desceu e ele ficava me perguntando se eu estava com medo. [...] parecia bipolar, de repente se transformava. Eu não vejo motivo pelo qual uma pessoa ir salvar um cachorro a outra chega e dar um soco na pilastra" (Acácia).
$\mathrm{Na}$ fala abaixo, Cacto expõe que não era agredida fisicamente pelo cônjuge por residir em uma comunidade, onde existem regras de sobrevivência.

"[...] quando você nasce e vive na periferia você conhece as pessoas, você não tá envolvida no tráfico, mas conhece as pessoas que estão. Então existe uma lei da favela, sabe?! Existe uma lei lá que funciona. Então homem não pode bater em mulher na favela" (Cacto).

Estudos apontam que possuir uma rede de apoio é fundamental para que a mulher em condição de violência consiga romper com as agressões sofridas e afasta- se do companheiro íntimo violento ${ }^{(33)}$. No entanto, nota-se no presente estudo que, por motivos culturais e pessoais, no início das agressões essas mulheres não expuseram o comportamento dos maridos e as situações violentas que vivenciavam, fazendo com que não denunciassem seus companheiros e seus familiares não tivessem conhecimento no primeiro momento dos episódios humilhantes e violentos que essas mulheres estiveram expostas, como caracterizado nas falas a seguir:

"Eu não queria preocupar meu pai e minha mãe, e ai eu resolvia meus problemas em tese. [...] Fracassar no casamento pra mim era uma coisa que eu não podia aceitar. Então meu casamento tinha que dar certo, nesse tinha que dar certo eu forcei essa barra" (Pinheiro).

"Ninguém sabia! Era só eu e Deus
somente e ele, né?! Mais ninguém
sabia, eu não contei pra ninguém,
até porque na época que eu estava
sofrendo isso, eu não cheguei a en-
tender e nem achava que era uma
agressão psicológica. Mas só depois
que eu pude entender como isso foi
prejudicial a mim" (Acácia).

A vista disso, é importante ressaltar que é necessário que o ciclo estrutural de violência contra a mulher seja desfeito, com a aliança de todos os componentes da sociedade com o objetivo de viabilizar ações favoráveis à integridade da saúde da mulher e sua família ${ }^{(34)}$.

\section{Rompendo com o ciclo da violência doméstica}

Há dentro da violência doméstica uma repetição de atos agressivos contra a mulher, chamado por ciclo da violência que possui três fases. A primeira delas é definida como acumulo da tensão, o homem responsável pela violência expõe uma conduta agressiva, menosprezando e desrespeitando sua companheira; o segundo momento é quando ocorre à explosão, nessa fase o agressor fica descontrolado, ocorrendo na maioria das vezes agressão física; a terceira e última fase é conhecida como lua-de-mel o companheiro reconhece que as suas atitudes foram inapropriadas e excessivas. É uma fase de tranquilidade e equilíbrio anormal, pedindo perdão e garantindo que não haverá mais violência, mas a agressão ocorre cada vez mais frequente e intensa ${ }^{(24)}$.

É necessário entender que há um tempo até que a mulher rompa com esse ciclo e consiga afastar-se do companheiro maltratante. Diferente do que é apresentado em alguns estudos, nos relatos abaixo percebe-se que após alguns anos as mulheres conseguiram romper com o ciclo da violência se apoiando no estudo, na militância, na afeição, bem querer e ternura.

"Foi à militância que me rebelou. Eu encontrei forças para gritar" (Pinheiro).

“[...] Eu não vou mais chorar porque eu sou inteligente, eu sou bonita" (Acácia).

"Comecei a olhar pra mim com mais amor. Então eu decidi que o dinheiro que eu gastava com ele, tempo, disposição, as minhas gargalhadas, a comida que eu fazia. Tudo que eu investia pra ele, passei 
a fazer pra mim. Investir em mim, amar a mim, brincar comigo, sair por mim. Engajar mais na luta." (Cacto).

Assim, é importante destacar que as mulheres dessa pesquisa que foram submetidas às agressões domésticas pelo parceiro íntimo superaram mais do que a violência psicológica. Elas conseguiram ultrapassar o medo de serem vítimas do feminicídio, o constrangimento sentido perante à sociedade, à solidão e todas as dificuldades que impediam o rompimento.

É significativo que as mesmas se sintam seguras em partilhar a violência vivida com as equipes de saúde, especificamente enfermeiros e que essas profissionais compreendam as especificidades destas mulheres, que não possuam quaisquer julgamentos, mas sim que reorientem essas mulheres para que tenham sua autoestima estimulada e que seja de sua própria vontate romper com este ciclo perverso.

É importante ressaltar a libertação que o feminismo ofereceu para a vida dessas mulheres, pois todas elas conseguiram se reconstruir no momento em que se aprofundaram na luta feminista e descobriram novas ideologias. Essas mulheres descobriram a força que possuiam e, através disso, tiveram coragem de romper com a vivência opressiva que estiveram submetidas durante os anos. A sororidade entre esse grupo está se intensificando cada vez mais com o passar dos dias. O apoio, a escuta empática, o afeto e o companheirismo são alguns dos principios que estão presentes na Rede das Pretas e nas mulheres que dela participam.

\section{CONCLUSÃO}

Foi constatado que a violência contra a mulher permanece sendo um problema de Saúde Pública, é indispensável que os órgãos governamentais estabeleçam ações e cuidados para com a mulher negra em situação de violência doméstica, no município de Cabo Frio, como Centros Especializados em atendimento e acolhimento a essas mulheres e seus filhos que estão em situação de violência doméstica, para que ocorra diminuição de agressão e morte contra as mulheres negras.

Ao observar detalhadamente as pesquisas, foi visto que alguns dados divergiam da literatura, em relação ao tipo mais comum de violência sofrida, a agressão física está em primeiro lugar, no entanto, na atual pesquisa houve uma prevalência da agressão psicológica. Outro dado interessante trata-se do perfil do agressor que em grande parte mostra-se ser um homem que possui o hábito de usar drogas e consumir bebidas alcoólicas, contudo, nessa pesquisa os homens não faziam uso de nenhuma substância psicoativa. Foi possível identificar a divergência na escolaridade das mulheres, pois nas literaturas as mulheres que so- frem violência doméstica grande parte não têm escolaridade elevada, todavia, todas as mulheres dessa pesquisa apresentam o ensino superior completo.

O principal propósito desse estudo foi dar voz e compreender quais são as necessidades destas mulheres, a fim de ser um protótipo de uma pesquisa que pode visar na reorientação das políticas públicas voltada a essas mulheres. Os profissionais da área da saúde, principalmente os enfermeiros, devem ter um escuta empática e proporcionar conforto e segurança para essas mulheres tenham coragem de denunciar seus agressores.

Houve limitações para a realização desta pesquisa: a indolência da Plataforma Brasil reduziu o período para tratamento de dados, o baixo número de sujeitos, pois essas mulheres sentiram vergonha em expor a violência vivida enquanto eram casadas com os agressores e também o tempo insuficiente para a realização de todo o estudo. No entanto, foi possível finalizar esta pesquisa e concluise que os objetivos foram alcançados, visto que foi possível descrever o impacto da violência doméstica sofrida nas mulheres negras no município de Cabo Frio. Apesar disso, essa pesquisa não pode finalizar em si, mas tem que ser apta a estimular a pesquisa dentro do tema violência, pois a sociedade, até o presente momento, ainda tem uma estrutura machista, um diálogo escasso e uma visão de violência familiar e domiciliar limitada.

\section{REFERÊNCIAS}

1. Organização Pan Americana de Saúde [Internet]. Folha informativa - Violência contra as mulheres [acesso em 20 de mar de 2019] Disponivel em: https://www.paho.org/bra/index.php?option=com_content\&view=article\&id=5669:folha-informativa-violencia- contra-as-mulheres\&ltemid=820

2. Poder Judiciário Estado do Rio de Janeiro [Internet]. Feminicidio [acesso em 27 de mar de 2019]. Disponivel em: http://www.tjrj.jus. br/web/guest/observatorio-judicial-violencia-mulher/feminicidio

3. Nações Unidas no Brasil. Direitos Humanos das Mulheres: a equipe das nações unidas no Brasil. Brasília: Nações Unidas no Brasil; 2018.

4.Fórum Brasileiro de Segurança Pública. Atlas da violência 2019.
Brasília: Fórum Brasileiro de Segurança Pública; 2019

5. Instituto Brasileiro de Geografia e Estatística [Internet]. População residente, por cor ou raça, segundo a situação do domicilio, o sexo e a idade. [acesso 05 de abri de 2019]. Disponível em: https:// sidra.ibge.gov.br/tabela/3175\#resultado

6. Ministério dos Direitos Humanos. Ligue 180 Central de Atendimento à Mulher. Brasilia: Ministério dos Direitos Humanos; 2018.

7. Ministério da Saúde (BR). Protocolos da atenção básica saúde das mulheres. Brasilia: Ministério da Saúde; 2016.

8. Senado Federal. Panorama da violência contra as mulheres no Brasil: indicadores nacionais e estaduais. Brasilia, 2018. 39p. 


\section{artigo}

Oliveira, T.S.; Duamarde, L.T.L.; Coura, E.A.; Faria, G.P.G.; Unsonst Filho, J.; Antunes, L.S.;

SORORIDADE NA ENFERMAGEM: dando voz às mulheres negras vítimas de violência

\section{REFERENCES}

9. Câmara dos Deputados Comissão de defesa dos direitos da muIher. Mapa da violência contra a mulher 2018. Brasília, 2018. 79p.

10. Presidência da República, Subchefia para Assuntos Jurídicos (BR). Lei n. ${ }^{\circ} 13.104$ de 9 de Março de 2015. Dispõe prever o feminicídio como circunstância qualidicadora do crime de homicídio e incluir o feminicídio no rol dos crimes hediondos [Internet]. Brasília, DF; 2015. [acesso em 08 de maio de 2019]. Disponivel em:http:// www.planalto.gov.br/ccivil_03/_ato2015-2018/2015/lei//13104. htm.

11. Petrucci G. Lei do Feminicídio e reconhecimento: Discussão crítica em torno dos remédios afirmativos para a violência de gênero. DOI [Internet]. 2018 [acesso em 05 de abr de 2019]; 1(26): 311-322. Disponível em: http://ojs.labcom-ifp.ubi.pt/index.php/ec/ article/view/201.

12. Tribunal de Justiça do Estado do Rio de Janeiro. Violência Doméstica e Familiar Contra a Mulher: nós vamos acabar com ela. Rio de Janeiro: Tribunal de Justiça do Estado do Rio de Janeiro; 2013.

13. Prodanov CC, Freitas EC. Metodologia do Trabalho Científico:métodos e técnicas da pesquisa e do trabalho acadêmico. 2. Ed. Rio Grande do Sul: Universidade Feevale; 2013.

14. Goldenberg M. A arte de pesquisar: como fazer pesquisa qualitativa em Ciências Sociais. 8. Ed. Rio de Janeiro: Record; 2004.

15. Conselho Nacional de Saúde (BR). Resolução n. ${ }^{\circ}$ 466, 12 de dezembro de 2012. Aprova diretrizes e normas regulamentadoras de pesquisas envolvendo seres humanos. Diario Oficial da União. 13 jun 2013: Seção 1.

16. Bardin L. Análise de Conteúdo. São Paulo: Edições; 2016.

17. Marconi MA, Lakatos EM. Metodologia do Trabalho Científico. 7. Ed. São Paulo: Editora Atlas S.A; 2015.

18. Sousa SD, Oshiro CP. Mulheres evangélicas e violência doméstica> o que o poder público e a igreja têm a ver com isso? Rev Caminhos [Internet]. 2018 [acesso em 30 de setembro de 2019]; 16 (2): 203-219. Disponível em: http://seer.pucgoias.edu.br/index.php/ caminhos/article/view/6730/3786.

19. Instituto Brasileiro de Direito da Familia [Internet]. CPC Simplifica separação de corpos [acessado em 10 novembro de 2019]. Disponivel em: http://ibdfam.org.br/noticias/5930/CPC+2015+simplifica+separa\%C3\%A7\%C3\%A30+de+corpos.

20. Franco DA, Magalhães AS, Carneiro TF. Violência Doméstica e Rompimento Conjugal: Repercussões do Litígio na Família. Rev Pensando Familias [Internet]. 2018 [acessado em 30 de Setembro de 2019]; 22(2): 154-171. Disponível em: http://pepsic.bvsalud. org/pdf/penf/v22n2/v22n2a11.pdf.

21. Presidência da República, Subchefia para Assuntos Jurídicos (BR). Altera a Lei n. ${ }^{\circ}$ 11.340, de 7 de agosto de 2006 (Lei Maria da Penha), para autorizar, nas hipóteses que especifica, a aplicação de medida protetiva de urgência, pela autoridade judicial ou policial, à mulher em situação de violência doméstica e familiar, ou a seus dependentes, e para determinar o registro da medida protetiva de urgência em banco de dados mantido pelo Conselho Nacional de Justiça [Internet]. Brasilia, DF; 2019. [acesso em 15 de novembro de 2019]. Disponivel em: http://www.planalto.gov.br/ccivil_03/_ ato2019-2022/2019/lei/L13827.htm.

22. Secretaria de Políticas para as Mulheres Presidência da República. Rede de enfrentamento: à violência contra as mulheres. Brasilia, 2011. 74p.

23. Leite FMC, Amorim MHC, Wehrmeister FC, Gigante DP. Violência contra a mulher em Vitória, Espírito Santo, Brasil. Rev Saúde Pública [Internet]. 2017 [acesso em 19 de abri de 2019]; 51(33): 1-12. Disponivel em: https://scielosp.org/pdf/rsp/2017.v51/33/pt.

24. Ministério da Saúde (BR). Violência Intrafamiliar Orientações para a Prática em Serviço. Brasilia: Ministério da Saúde; 2002.

25. Presidência da República, Subchefia para Assuntos Jurídicos (BR). Lei n. ${ }^{\circ} 11.340$ de 7 de Agosto de 2006. Dispõe mecanismos para coibir a violência doméstica e familiar contra a mulher [Internet]. Brasília, DF; 2006. [acesso em 17 de setembro de 2019]. Disponível em: http://www.planalto.gov.br/ccivil_03/_ato20042006/2006/lei/l11340.htm.

26. Centro de Estudos Judiciários. Violência Doméstica: Implicações sociológicas, psicológicas e jurídicas do fenômeno [Internet]. Brasília: CC Outro; 2016 [acesso em 26 de setembro 2019]. Disponível em: http://www.cej.mj.pt/cej/recursos/ebooks/outros/Violencia-Domestica-CEJ_p02_rev2c-EBOOK_ver_final.pdf.

27. Organização Mundial da Saúde. Relatório mundial sobre violência e saúde [Internet]. Genebra: OMS; 2002. [acesso em 26 de setembro de 2019]. Disponivel em: https://www.opas.org.br/wp-content/uploads/2015/09/relatorio-mundial-violencia-saude.pdf.

28. Rujine RE, Howard LM, Trevillion K, Jongejan FE, Garofalo C, Bogaerts $\mathrm{S}$, et al. Detection of domestic violence by community mental health teams: a multicenter, cluster randomized controlled Trial. BMC Psychiatry. 2017; 17:288

29. Secretaria de Estado de Saúde do Distrito Federal. Manual para atendimento às vítimas de violência na rede de saúde pública do DF. Brasilia: Secretaria de Estado de Saúde do Distrito Federal; 2009

30. Organização Mundial da Saúde. Relatório mundial sobre violência e saúde [Internet]. Genebra: OMS; 2002. [acesso em 26 de setembro de 2019]. Disponivel em: https://www.opas.org.br/wp-content/uploads/2015/09/relatorio-mundial-violencia-saude.pdf.

31. Secretaria Especial de Políticas para as Mulheres. Enfrentando a violência contra a mulher - Orientações Práticas para Profissionais e Voluntários(as). Brasília, 2005. 64p.

32. Geledés Instituto da Mulher Negra [Internet]. Violência doméstica e familiar contra a mulher - A lei Maria da Penha: uma análise jurídica. [acesso em 02 de novembro 2019]. Disponivel em: https:// www.geledes.org.br/violencia-domestica-e-familiar-contra-muIher-lei-maria-da-penha-uma-analise-juridica/.

33. . Albuquerque Netto L, Moura MAV, Araujo CLF, Souza MHN, Silva GF. As redes sociais de apoio às mulheres em situação de violência pelo parceiro íntimo. Enferm. 2017; 26(2): e07120015.

34. Lemos ACS. Violência infligida por parceria íntima no contexto da mulher quilombola [monografia]. Santo Antônio de Jesus: Universidade Federal do Recôncavo da Bahia; 2017. 